\title{
Near-field flow downstream of a barrage: Experiments, 3-D CFD and depth-averaged modelling
}

DOI:

10.1115/OMAE2011-50291

Link to publication record in Manchester Research Explorer

\section{Citation for published version (APA):}

Jeffcoate, P., Stansby, P. K., \& Apsley, D. (2011). Near-field flow downstream of a barrage: Experiments, 3-D CFD and depth-averaged modelling. In Proceedings of the International Conference on Offshore Mechanics and Arctic Engineering - OMAE/Proc Int Conf Offshore Mech Arct Eng - OMAE (Vol. 5, pp. 909-918) https://doi.org/10.1115/OMAE2011-50291

Published in:

Proceedings of the International Conference on Offshore Mechanics and Arctic Engineering - OMAE|Proc Int Conf Offshore Mech Arct Eng - OMAE

\section{Citing this paper}

Please note that where the full-text provided on Manchester Research Explorer is the Author Accepted Manuscript or Proof version this may differ from the final Published version. If citing, it is advised that you check and use the publisher's definitive version.

\section{General rights}

Copyright and moral rights for the publications made accessible in the Research Explorer are retained by the authors and/or other copyright owners and it is a condition of accessing publications that users recognise and abide by the legal requirements associated with these rights.

\section{Takedown policy}

If you believe that this document breaches copyright please refer to the University of Manchester's Takedown Procedures [http://man.ac.uk/04Y6Bo] or contact uml.scholarlycommunications@manchester.ac.uk providing relevant details, so we can investigate your claim.

\section{OPEN ACCESS}




\section{OMAE2011-50291}

\section{NEAR-FIELD FLOW DOWNSTREAM OF A BARRAGE: EXPERIMENTS, 3-D CFD AND DEPTH-AVERAGED MODELLING}

\author{
Penelope Jeffcoate \\ University of Manchester \\ Manchester, UK
}

\author{
Prof. Peter K. Stansby \\ University of Manchester \\ Manchester, UK
}

\author{
Dr. David Apsley \\ University of Manchester \\ Manchester, UK
}

\section{ABSTRACT}

Tidal schemes such as the Mersey Barrage are being considered for UK energy generation, because barrage electricity generation is renewable, reliable and predictable and creates no toxic by-products.

A key problem perceived to arise from barrages is the detrimental environmental impact, which may include changes in water levels, which affects species like wading birds; altered water turbidity, which affects fish and plant species; and changes to sediment drift patterns, potentially causing sediment or pollution trapping. Some of these, however, may be positive outcomes of the barrage.

In order to assess the accuracy of two-dimensional, depthaveraged models that are commonly used for large-scale modelling, flume experiments and 3-D computations have been undertaken to compare with depth-averaged modelling.

The 2-D model was found to be inaccurate in predicting the close-to-surface flow patterns close to the barrage, however further from the barrage the model accurately predicted the approximate velocity magnitude at the surface.

The 3-D model accurately predicted the velocity profiles at the depths and distances from the barrage that were analysed, with a few exceptions.

Both models need altering and refining in order to obtain reasonable results for the friction velocity and bed shear stress, and this will be a further development of this project.

\section{INTRODUCTION}

Previous depth-averaged (i.e. two-dimensional (2-D)) computer modelling of tidal barrages has been used to predict turbine power and hydro-environmental effects, such as water quality and sediment and bacterial concentrations (Ahmadian et al (2010)). Depth-averaging, however, assumes there is no variation of velocity across depth.

Jets have been modelled intensively, issuing from pipes which are of a similar form to the turbine culverts; non-buoyant jets in shallow-water have been modelled, however there has been little modelling of multiple jet arrays. Huai and Toshihiko (1999) investigated multiple non-buoyant jets entering shallowwater using a $\mathrm{k}-\varepsilon$ turbulence model and wall functions, however the flow entered a cross-flow, so the jet characteristics were different from those expected in this project.

Previous modelling has also been large scale, looking at velocity and water-level changes across the whole estuary (Xia et al (2010)). Close to the barrage, within a few hundred metres, the water turbulence, turbidity and velocity may be very different from previous predictions, due to characteristics such as strong flow curvature.

In order to determine how the velocity may change throughout the depth, in particular near to the barrage, threedimensional (3-D) modelling can be used, with experimentation to verify whether the results produced are acceptable. The 3-D results can be compared with 2-D modelling results to determine whether the 2-D modelling produces a viable representation of the flow downstream from the barrage. The friction velocities predicted by the each method could also be compared; these affect the bed stresses which are vital to sediment transport processes.

\section{NOMENCLATURE}

$\begin{array}{ll}\mathrm{D} & \text { Culvert diameter }(\mathrm{m}) \\ \mathrm{h}_{1} & \text { Upstream water height }(\mathrm{m}) \\ \mathrm{h}_{2} & \text { Downstream water height }(\mathrm{m}) \\ \mathrm{H} & \text { Head difference }(\mathrm{m}) \\ \beta & \text { Horizontal to vertical mixing length ratio } \\ \mathrm{Q} & \text { Discharge }\left(\mathrm{m}^{3} / \mathrm{s}\right) \\ \mathrm{R} & \text { Turbine radius }(\mathrm{m}) \\ \mathrm{U}_{\text {in }} & \text { Inlet velocity }(\mathrm{m} / \mathrm{s}) \\ \mathrm{U}_{\text {mean }} & \text { Cross-section-averaged velocity }(\mathrm{m} / \mathrm{s}) \\ \mathrm{U}^{*} & \text { Friction velocity }(\mathrm{m} / \mathrm{s}) \\ \mathrm{U}, \mathrm{V}, \mathrm{W} & \text { Velocities in } \mathrm{X}, \mathrm{Y}, \mathrm{Z} \text { direction }(\mathrm{m} / \mathrm{s}) \\ \mathrm{X}, \mathrm{Y}, \mathrm{Z} & \text { Length, Breadth, Depth }(\mathrm{m})\end{array}$




\section{EXPERIMENTS AND MODELLING}

\section{Experiments}

A 1:140 scale model was constructed based upon the barrage detailed in DEP Energy Paper (1981). The turbine culverts were changed to cylinders of radius, $R=0.055 \mathrm{~m}$; currently no turbine representation is included. The model was scaled to fit the experimental tank, so the barrage dimensions were $0.539 \mathrm{~m} \times 1.22 \mathrm{~m} \times 0.28 \mathrm{~m}$. Seven culverts were built into the barrage and a Vectrino ADV with gantry was assembled downstream from the barrage. The downstream depth was set using a weir at $2.8 \mathrm{~m}$ downstream from the barrage. The experimental set-up is shown in Fig 1:

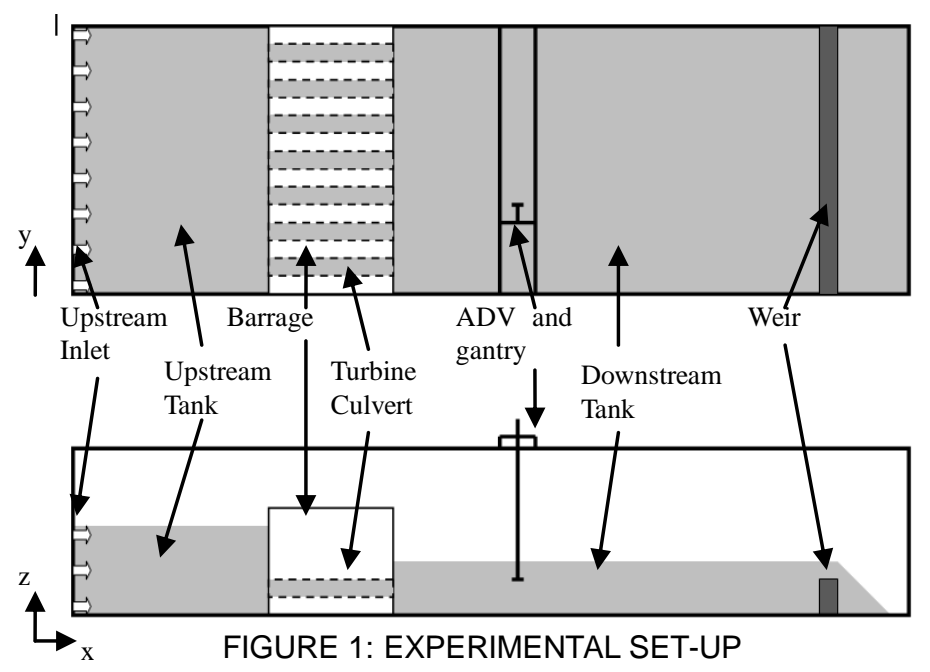

The discharge was set so that the culverts were fully submerged; the average inlet discharge, $\mathrm{Q}$, was $0.0291 \mathrm{~m}^{3} / \mathrm{s}$, the average upstream height, $\mathrm{h}_{1}$, was $0.2326 \mathrm{~m}$, so the average inlet velocity, $\mathrm{U}_{\text {in }}$, was $0.1025 \mathrm{~m} / \mathrm{s}$. The average head difference, $\mathrm{H}$, was $0.017 \mathrm{~m}$, since the average downstream height, $\mathrm{h}_{2}$ was $0.2156 \mathrm{~m}$. The depths at various locations along the tank were also recorded.

The velocity profiles across the tank were recorded at distances 1D, 2D and 20D downstream, where $D=0.11 \mathrm{~m}$ is the culvert diameter. The stream-wise and span-wise velocities were recorded at depths of $0.04 \mathrm{~m}, 0.08 \mathrm{~m}, 0.12 \mathrm{~m}, 0.16 \mathrm{~m}$ and $0.0195 \mathrm{~m}$ from the bed at $1 \mathrm{D}$ and $2 \mathrm{D}$ and $0.0185 \mathrm{~m}$ at $20 \mathrm{D}$. These results were then used to assess the variation of velocity throughout the depth, the depth-averaged velocities and the ratio of bed velocity magnitude to mean velocity magnitude.

\section{3-D Modelling}

The experimental set-up was replicated as a 3-D simulation using the computational fluid dynamics (CFD) package StarCCM+. This solves the Reynolds-averaged Navier-Stokes (RANS) equations with a standard k- $\varepsilon$ turbulence model (Launder and Spalding (1974)), with high Reynolds number wall treatment. Other turbulence models, a non-linear and a realizable $\mathrm{k}-\varepsilon$ model, were tested, but the results were unchanged so the standard model was used for the simulations.
The computational domain extended $1.1 \mathrm{~m}$ upstream and $2.8 \mathrm{~m}$ downstream of the turbine culverts. The tank depths were set to the experimental water depths; upstream, $\mathrm{h}_{1}$, and downstream, $h_{2}$. The free surface was treated as a rigid lid with no slip (zero stress) boundary condition.

The model was meshed with an unstructured polyhedral mesh with base size $0.02 \mathrm{~m}$ (Fig 2); the culvert mesh and downstream tank close to the barrage used refinement up to $0.005 \mathrm{~m}$., approximately $10 \%$ of the pipe diameter, to resolve internal pipe flow and the jet exit The model is uniform across the depth with 9 cells and width with 36 cells; the longitudinal cell size increases with downstream distance to the base size. The model had a total of 113582 cells. Preliminary mesh sensitivity studies were conducted and this cell geometry was found to give reasonable results. Further formal convergence tests of the mesh design and time interval are ongoing.

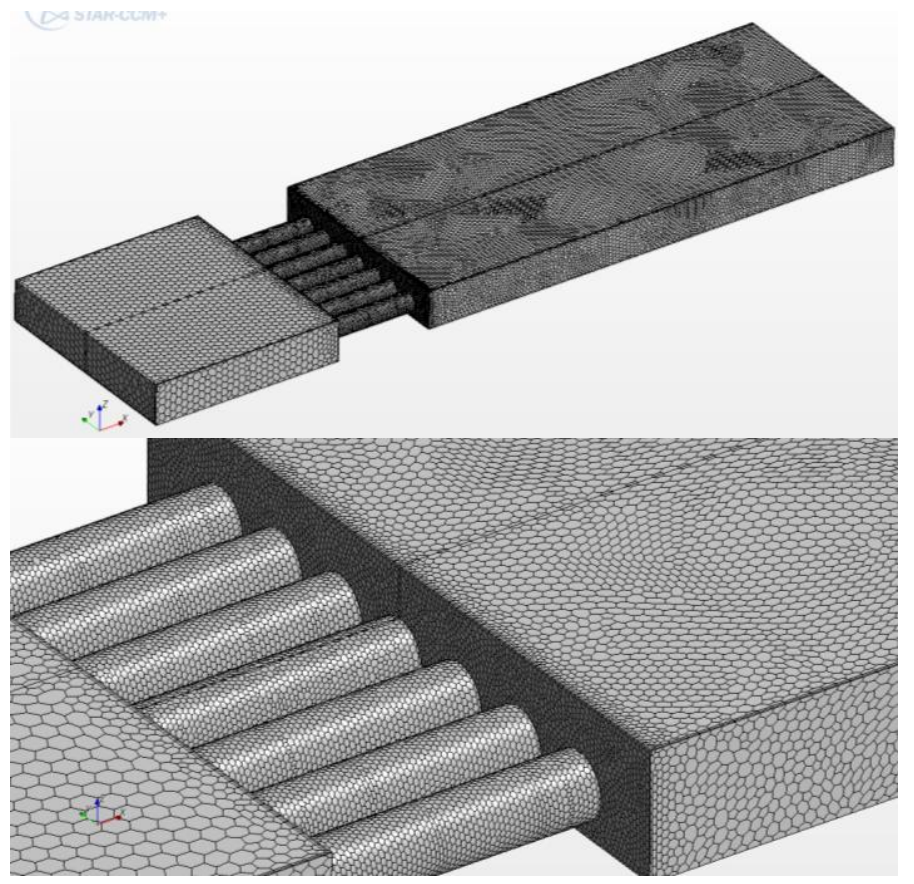

FIGURE 2: STARCCM+ MODEL MESH

The inlet boundary was defined as a velocity inlet with the same velocity as the experiment. The walls and floor were modelled as smooth walls to represent the experimental tank. The surface was modelled as a slip wall to represent the free surface and the downstream boundary was set as a constant pressure/head outlet. Only half the tank was modelled with lateral symmetry assumed.

The three component velocities were output at $0.04 \mathrm{~m}$, $0.08 \mathrm{~m}, 0.12 \mathrm{~m}, 0.16 \mathrm{~m}$ and $0.0195 \mathrm{~m}$ from the bed at $1 \mathrm{D}$ and $2 \mathrm{D}$ and $0.0185 \mathrm{~m}$ at $20 \mathrm{D}$ downstream from the turbine passages; the shear stress on the bed at these distances downstream was also recorded. These results were then used to assess the variation of velocity throughout the depth, the depth-averaged velocities and the ratio of bed velocity magnitude to mean velocity magnitude. 


\section{2-D Modelling}

A depth-averaged model called SW2D, detailed in Stansby (2006), was used. The SW2D code is a finite volume simulation of shallow water equations with a turbulent mixing coefficient. The semi-implicit model uses second order time stepping, a QUICK (Quadratic Upstream Interpolation for Convective Kinematics) advection scheme and CGS (Conjugate Gradient Solver).

The model represents the downstream tank and the mesh has 200 cells in the stream-wise direction by 100 cells in the span-wise direction. A preliminary mesh sensitivity studied was undertaken which showed that this mesh refinement produced the results with the best correlation with the experimental and StarCCM+ results. Further mesh sensitivity and time interval studies are also ongoing for the 2-D program.

The model requires the input of the upstream flow rate and the downstream depth, which were determined from the experiments. The experimental discharge rate, number of turbines, turbine radius and centreline spacing were also input. The position of the turbines was specified so that one turbine centreline was at mid width in the tank, thus the tank was symmetrical about the centreline. A quarter sine variation ramp up for flow rate was used which ran over $25 \mathrm{~s}$, with the total run time of $100 \mathrm{~s}$ and a time step of $0.0002 \mathrm{~s}$.

At the upstream boundary a uniform velocity, chosen to give the correct total discharge, was applied at cells coinciding with the outlets. Smooth walls were assumed for the tank sides and the downstream boundary condition was specified as a water depth.

The program outputs the velocity vectors at each cell and the surface elevation. The velocities across the width were determined at various locations downstream from the barrage and the friction velocities were calculated.

The stream-wise and span-wise depth-averaged velocities were recorded at 1D, 2D and 20D. These results were then used to assess the depth-averaged velocities and the ratio of friction velocity to cross-section-averaged velocity.

\section{RESULTS}

\section{Water Height Variation}

The experimental water depths immediately upstream, immediately downstream and at 1D, 2D, 3D, 5D, 10D, 15D and 20D from the barrage were recorded and are shown in Fig 3.

The water level drops across the barrage by $0.017 \mathrm{~m}$ and over the next $20 \mathrm{D}$ by $0.01 \mathrm{~m}$. Due to this reduction in water level the close-to-surface velocity measurements for $1 \mathrm{D}$ and $2 \mathrm{D}$ were taken at $0.195 \mathrm{~m}$ from the bed, whilst at $20 \mathrm{D}$ they were taken at $0.185 \mathrm{~m}$ from the bed.

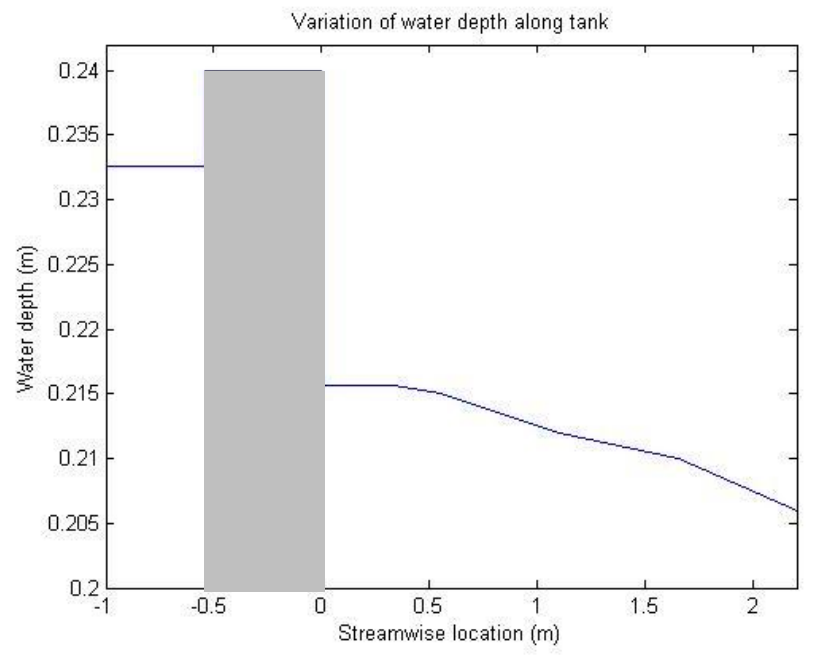

FIGURE 3: VARIATION OF WATER DEPTH DOWNSTREAM

\section{Velocity Vectors}

The velocity vectors produced by the 2-D SW2D model are shown below in Fig 4:

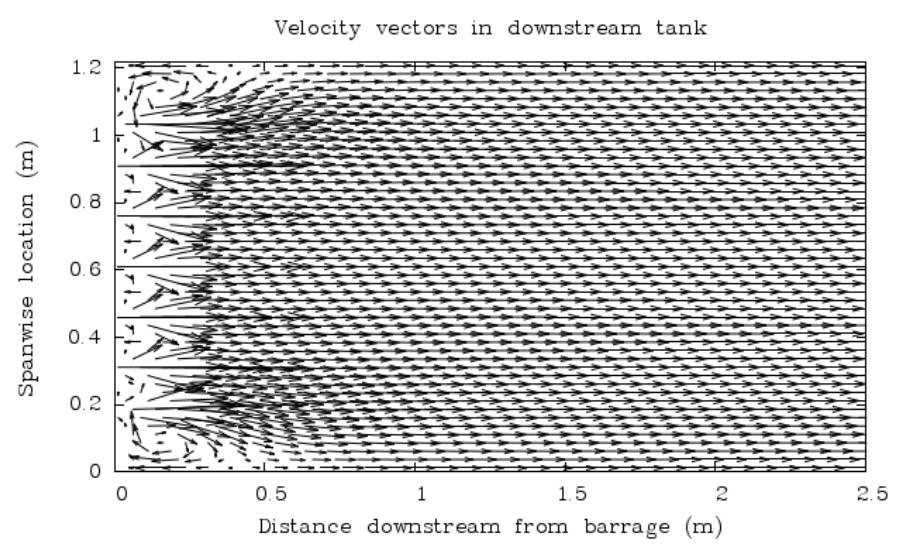

FIGURE 4: VELOCITY VECTORS PRODUCED BY SW2D

The seven jets seen show the location of the jets downstream from the turbine culverts. Eddies at the tank sides occur close to the barrage outlet. This circulation is also evident in the mid-plane vector plot produced by StarCCM+ (Fig 5). This recirculation can be seen to force the outermost jets towards the centre of the tank.

These flow features were evident in the analysis of the velocities across the width of the tank; both the variation of the flow velocities at different depths and the depth-averaged velocities were assessed. 


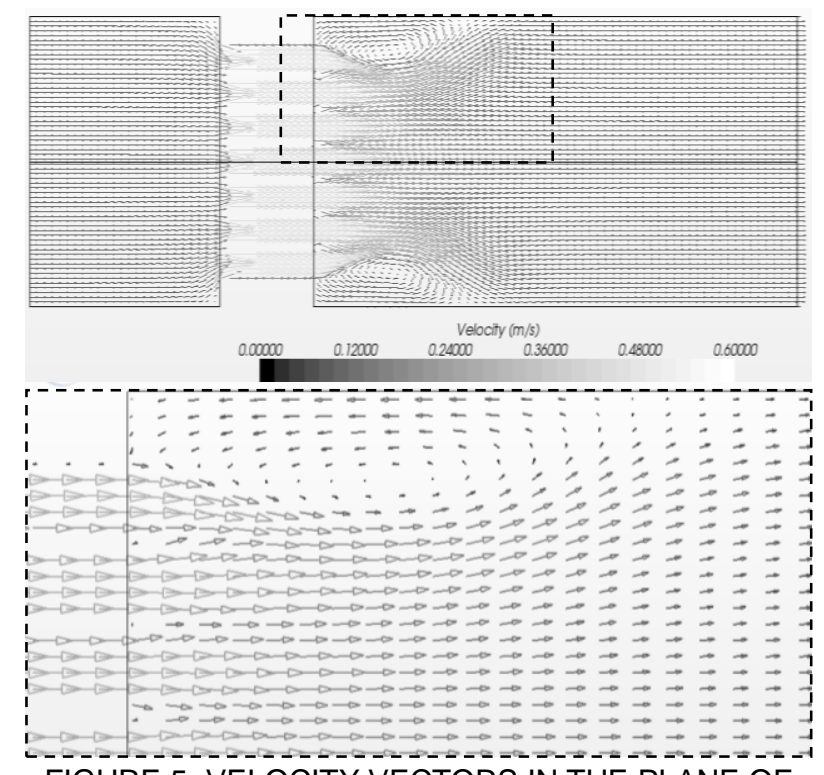

FIGURE 5: VELOCITY VECTORS IN THE PLANE OF TURBINE CENTRELINES PRODUCED BY STARCCM+

\section{Depth-varying velocity}

The variation of velocity throughout the depth was analysed using experimentation and 3-D computational modelling. The stream-wise velocity profiles across the width at the various depths at 1D, 2D and 20D are shown in Fig 6, Fig 7 and Fig 8 respectively.

At 1D downstream from the barrage (Fig 6), at $0.04 \mathrm{~m}$ from the bed, the stream-wise velocity increases directly downstream of each turbine culvert and both the experimental and computational results predict a similar peak velocity. The flow velocity between each of the culverts decreases, but remains positive; however, the flow between the outermost jet and the tank wall reverses, due to the formation of eddies on each side. The eddy size predicted by the experiments and the CFD model can also be seen to be similar, because the stream-wise velocity component becomes positive at the same y location.

At $0.08 \mathrm{~m}$ from the bed a similar velocity pattern is shown, with peaks directly downstream of the culverts and eddies at the tank edges. The peak velocities are similar to before, although slightly higher, probably because the turbine centreline is located

Streamwise velocity at various depths at One $D$ downstream

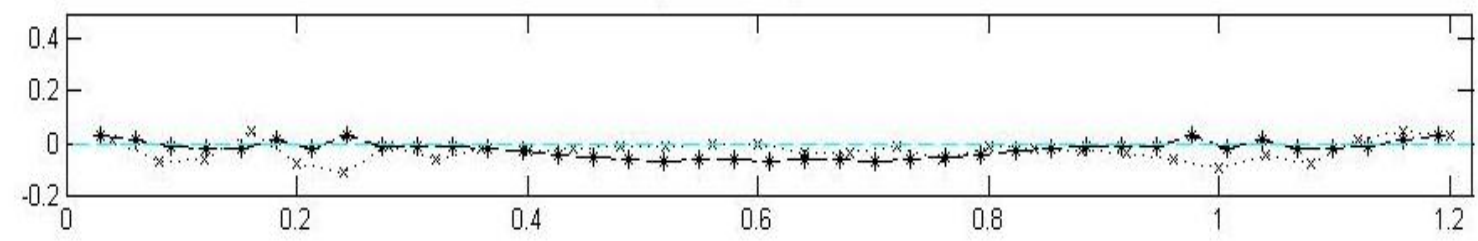

$\cdots \times \cdots$ Experimental $d=0.195 \mathrm{~m}$

-* - Computational $\mathrm{d}=0.195 \mathrm{~m}$
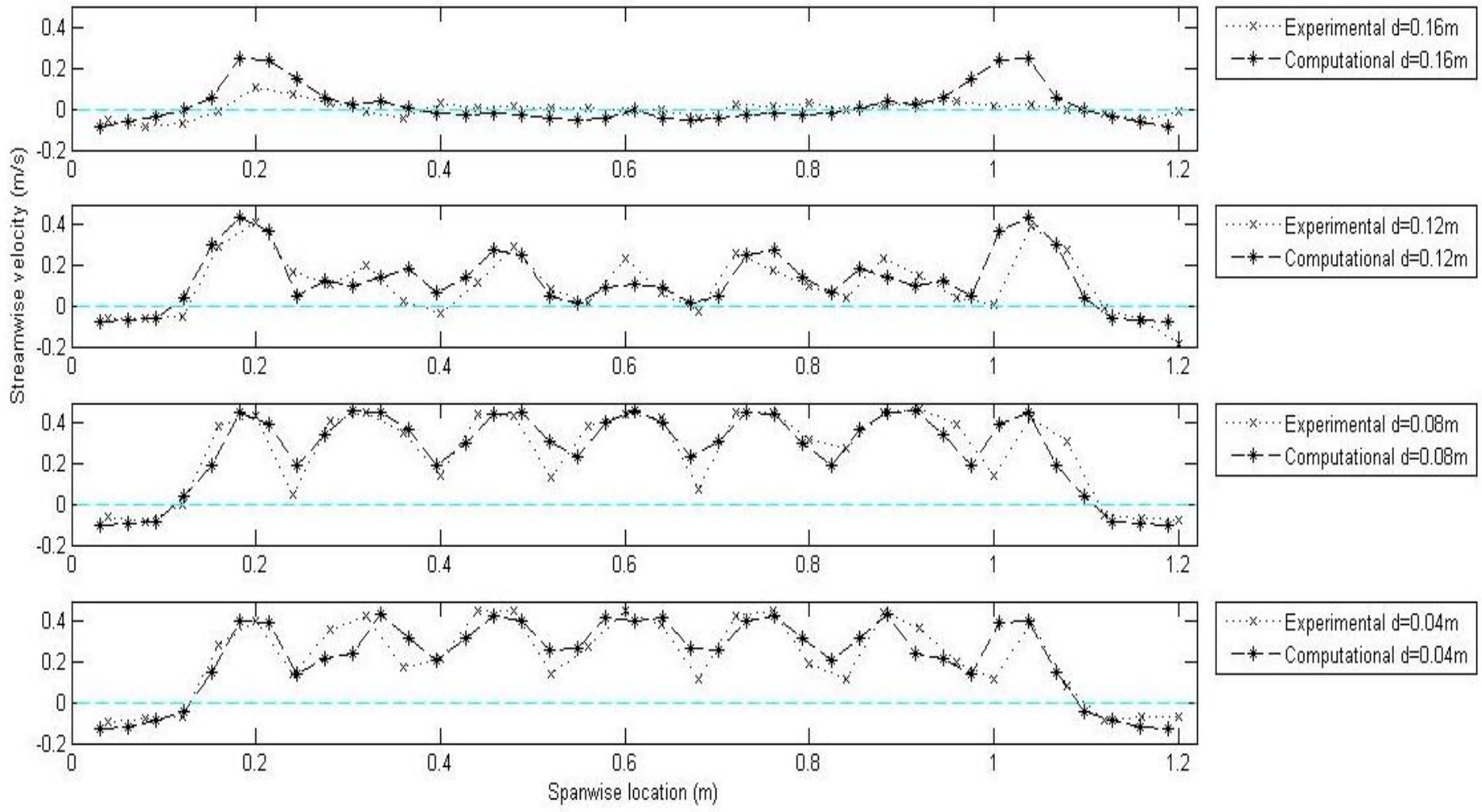

FIGURE 6: STREAMWISE VELOCITY AT 0.04m, 0.08m, 0.12m, 0.16m AND 0.195m FROM THE BED AT ONE D DOWNSTREAM USING EXPERIMENTS AND 3-D COMPUTATION 
at $0.0725 \mathrm{~m}$, so both the profiles at $0.04 \mathrm{~m}$ and $0.08 \mathrm{~m}$ are within the culvert. The outermost jets predicted by the model are closer to the centreline than in the experiments, which is most evident at the right-hand jet in Fig 2. This may be due to the forcing of the jets into the centre by the eddies which was shown in Fig 5. The eddies are slightly smaller than those at $0.04 \mathrm{~m}$, but the peak reverse velocity is approximately the same.

At $0.12 \mathrm{~m}$ from the bed, the velocity profiles are similar to the previous profiles, however the inner jets are less defined than before and the maximum velocity is reduced; also the velocity also occasionally drops below zero, indicating reversed flow. The correlation between the experimental and computational results is less defined at this depth, but the maximum and minimum velocities are approximately the same.

The profile at $0.16 \mathrm{~m}$ has several differences to the lower profiles; the experimental eddy size is smaller than that predicted by the model and smaller than at the previous depths. The experimental outer jets have a much lower velocity; also, the outermost jets from the computation still produce the peak velocities, however this has reduced from approximately
$0.45 \mathrm{~m} / \mathrm{s}$ to $0.25 \mathrm{~m} / \mathrm{s}$. For both experimental and computational results, the velocity between the jets is mostly negative and has a range between $-0.05 \mathrm{~m} / \mathrm{s}$ and $0.02 \mathrm{~m} / \mathrm{s}$.

At $0.195 \mathrm{~m}$ from the bed the velocity pattern shown at the other depths is no longer evident; the eddies at the tank edges are not formed at this depth, however there may be areas of vertical recirculation, shown by the negative flow directly above the outermost jets. This feature is stronger in the experimental results. The negative flow between these outer jets shows that the flow close to the surface is reversed, which indicates that the spreading of the jets occurs in the vertical direction too, leading to a stream-wise eddy forming across most of the tank.

The stream-wise velocity profiles at $2 \mathrm{D}$ downstream were also analysed and the results are shown in Fig 7. At $0.04 \mathrm{~m}$ from the bed the velocity pattern is similar to that seen at 1D downstream, but the peaks and troughs of the velocities across the width are less defined than at $1 \mathrm{D}$, due to the spreading of the jets. The peak velocities have also decreased and the velocity range downstream from the culverts has reduced. The

Streamwise velocity at various depths at Two $D$ downstream
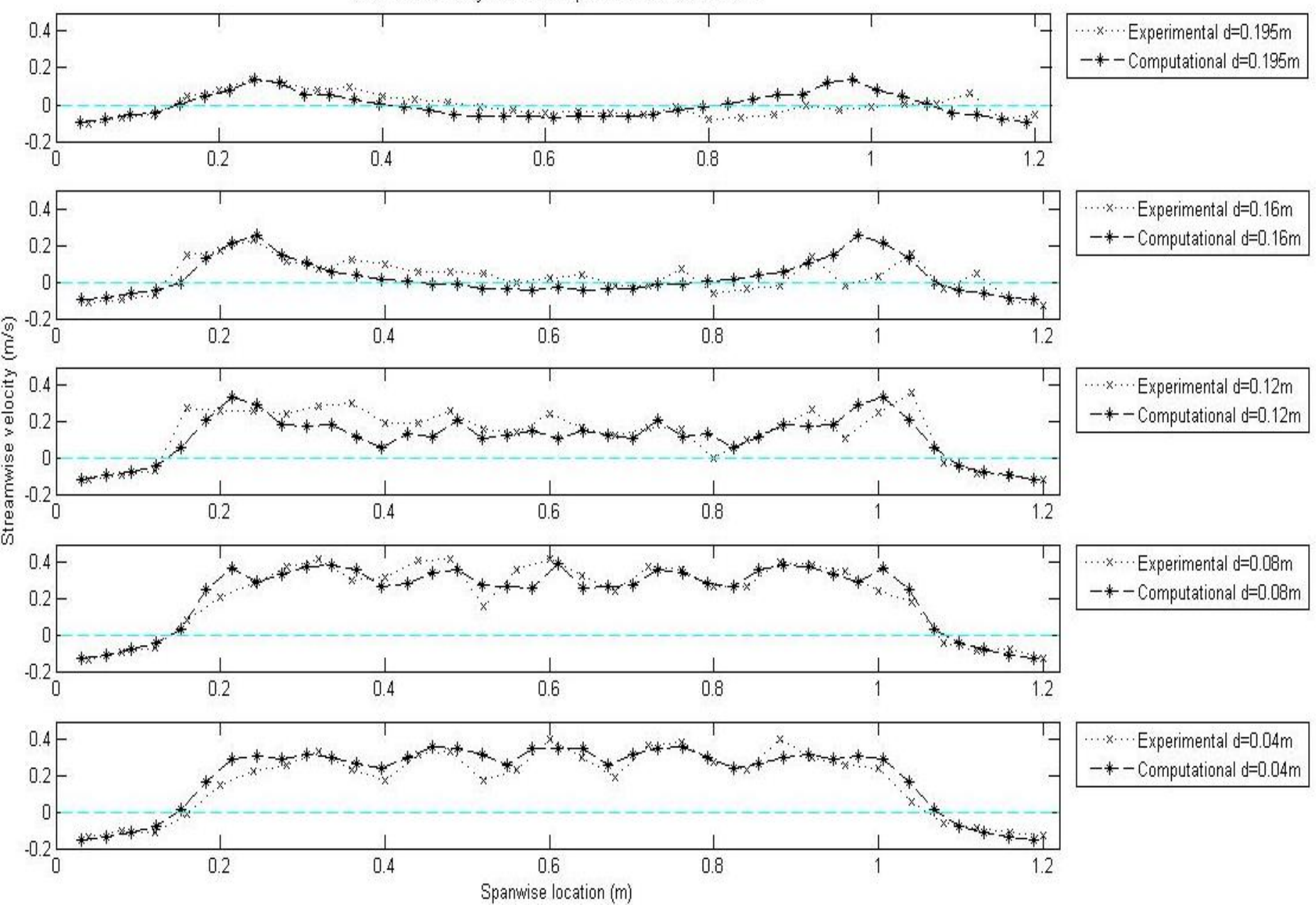

FIGURE 7: STREAMWISE VELOCITY AT $0.04 \mathrm{~m}, 0.08 \mathrm{~m}, 0.12 \mathrm{~m}, 0.16 \mathrm{~m}$ AND $0.195 \mathrm{~m}$ FROM THE BED AT TWO D DOWNSTREAM USING EXPERIMENTS AND 3-D COMPUTATION 
correlation between the experimental values and computational values is less defined at this distance downstream, but the location and size of the eddies and location of the jet edges is the same.

This pattern is seen at $0.08 \mathrm{~m}$ from the bed as well. At this depth the eddies appear to force the experimental jets closer to the centreline, unlike the outermost jets in the computational results. The location and magnitude of the inner jets are similar between the two sets of results, however there is some asymmetry in the experimental results.

At $0.12 \mathrm{~m}$ the maximum velocity drops and, similar to the flow at $1 \mathrm{D}$, the outermost jets become most prominent and the inner jets decrease in magnitude. The experimental outer jets have more spreading than the computational jets, but the eddy size and peak velocity locations are still very similar.

At $0.16 \mathrm{~m}$ the jets of the inner computational jets begin to become negative, as the flow starts to reverse direction. The experimental and computational eddies are of a similar size and the magnitude of the reversed flow is similar to the flow at 1D.

For the close-to-surface flow, at $0.0195 \mathrm{~m}$, the flow profile is very similar to that at $0.16 \mathrm{~m}$, but the peak velocities are reduced. There is also still an eddy at the tank edge, unlike the close-to-surface profile at $1 \mathrm{D}$. The velocity patterns at all the depths except the close- to-the-surface are very similar between $1 \mathrm{D}$ and $2 \mathrm{D}$ downstream, but with more spreading and reduced velocity at $2 \mathrm{D}$.

The flow patterns much further from the barrage, at 20D, are quite different from those close to the barrage (Fig 8). All of the profiles have a similar velocity of approximately $0.1 \mathrm{~m} / \mathrm{s}$, but the velocities closer to the surface are slightly lower than those closer to the bed. At the edges and the middle of the profile there is a slight peak in the velocities, in both the experimental and computational results.

There is a strong correlation between the experimental results and the 3-D StarCCM+ results. There is also little change in the velocity magnitude and profiles at the various water depths.
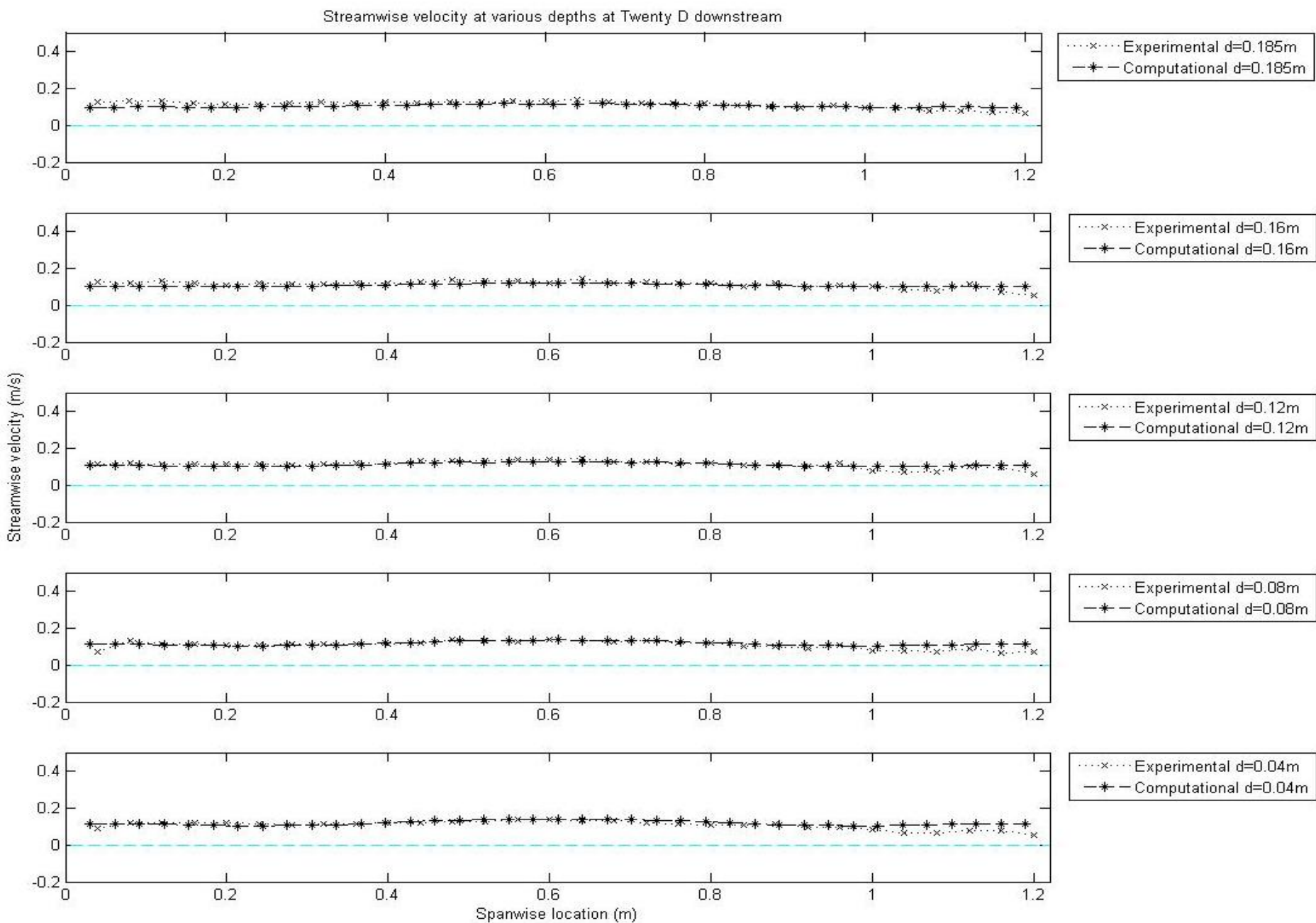

FIGURE 8: STREAMWISE VELOCITY AT $0.04 \mathrm{~m}, 0.08 \mathrm{~m}, 0.12 \mathrm{~m}, 0.16 \mathrm{~m}$ AND $0.185 \mathrm{~m}$ FROM THE BED AT TWENTY D DOWNSTREAM USING EXPERIMENTS AND 3-D COMPUTATION 


\section{Depth-averaged velocity}

The SW2D program produces the depth-averaged streamwise and span-wise velocities downstream from the barrage; the stream-wise results have been analysed at 1D, 2D and 20D. The 3-D results produced by the experimentation and StarCCM+ computation were depth-averaged at the 1D, 2D and 20D; the experimental velocity values at each span-wise location were averaged across the depth, so the velocity values at $0.04 \mathrm{~m}$, $0.08 \mathrm{~m}, 0.12 \mathrm{~m}, 0.16 \mathrm{~m}$ and $0.195 \mathrm{~m}$ were averaged. For the 3D modelling, all of the velocity values throughout the depth at a given number of span-wise locations were averaged (Fig 9).

At 1D downstream from the barrage, the flow is reversed at the tank edges, indicating the presence of eddies; all of the analysis methods produce this result. The 2-D program predicts a slightly smaller eddy than the 3-D methods, but the peak velocity for all three occurs at approximately the same location. The experimental and StarCCM+ peaks and troughs of the jets occur slightly closer to the centreline of the tank than the SW2D results. The StarCCM+ results have the smallest velocity range and the SW2D results have the largest range.
At $2 \mathrm{D}$ the results show good correlation between all the methods of analysis for the centre three culvert jets. The SW2D outer jets show more spreading than the other results, plus the StarCCM+ outer jets show a higher peak velocity. Towards the tank edges an eddy still occurs, but the 3-D results show a larger eddy with a higher reverse velocity.

The spreading rate of the SW2D model is dependent on the $\beta$ factor, which is the horizontal to vertical mixing length ratio; $\beta$ currently equals 1 , however if it is increased to 3 then the velocity magnitude of the peaks and troughs is similar to the 3$\mathrm{D}$ models. If the $\beta$ is increased, however, then too much spreading occurs at 2D downstream. This parameter may need to be refined to establish the best results for all distances from the barrage.

At 20D all of the results are similar showing a fairly constant velocity value of $0.1 \mathrm{~m} / \mathrm{s}$ across the whole width. There are a couple of differences between the results; the SW2D results show maximum velocities at the outer jet locations across the tank and a minimum at the tank centre, whereas the opposite is true of the 3-D results.
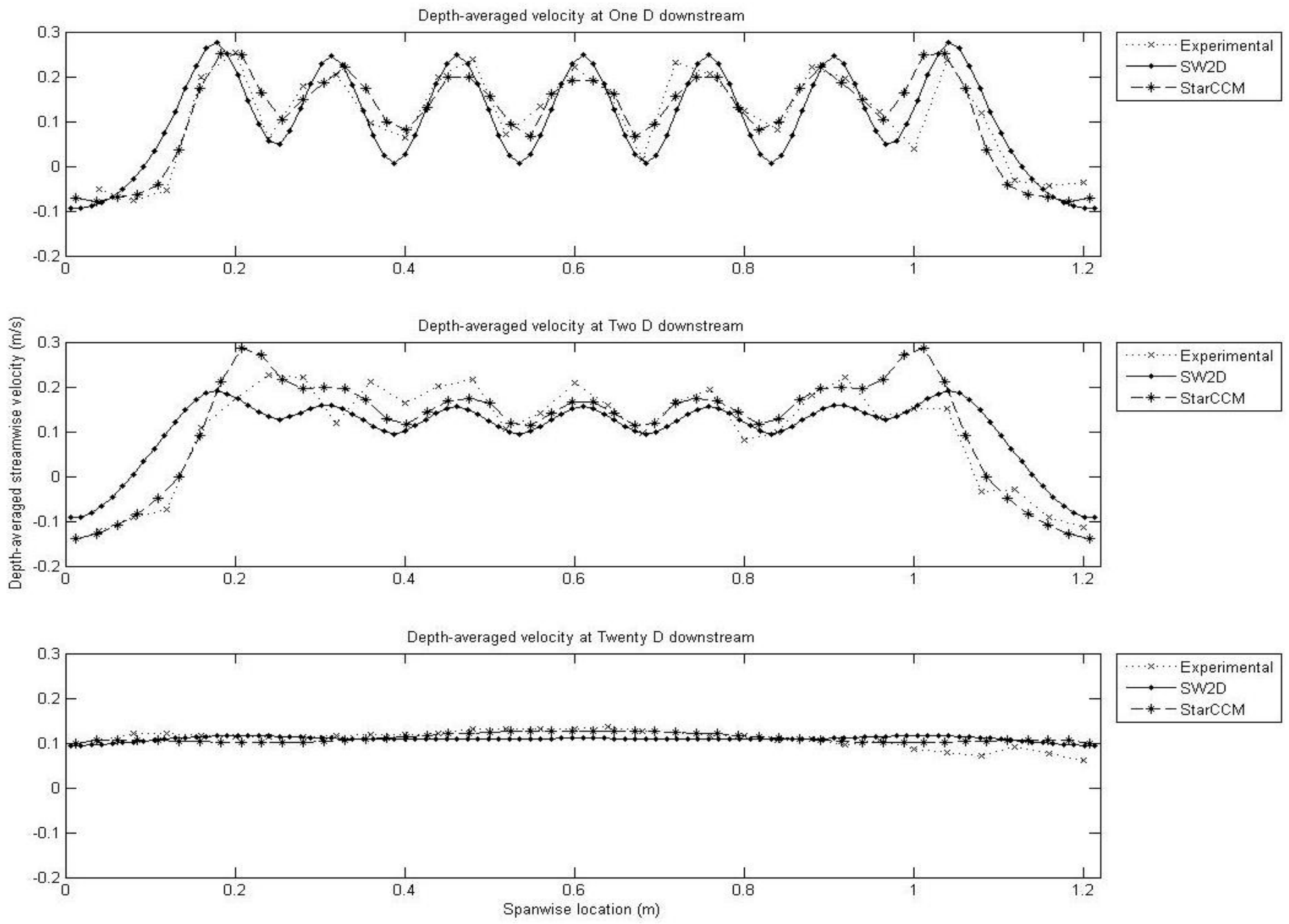

FIGURE 9: DEPTH-AVERAGED STREAMWISE VELOCITY AT 1D, 2D and 20D USING EXPERIMENTS, 2-D AND 3-D

COMPIJTATION 


\section{Bed friction velocity}

The ratio of friction velocity $\left(\mathrm{U}^{*}\right)$ to cross-section-averaged velocity $\left(\mathrm{U}_{\text {mean }}\right)$ was analysed for StarCCM+, experiments and SW2D at 1D, 2D and 20D; these results are shown in Fig 10.

The wall shear stress and density at the bed of the StarCCM+ model were used to find the friction velocity. Using the StarCCM+ ratios of friction velocity to velocity magnitude at $0.01 \mathrm{~m}$, the friction velocity from the experimental results were inferred. The friction velocity of the SW2D program was found using the coefficient of friction, specified as 0.01 . The cross-section-averaged velocity was determined from the inlet discharge and the cross-sectional area.

At 1D downstream there is little correlation between the StarCCM+, experimental and SW2D results; the StarCCM+ results are symmetrical like the SW2D results, however the SW2D results show seven defined peaks whereas StarCCM+ has large outer peaks but merged inner peaks. The experimental results are asymmetrical, but the outer jets occur at approximately the same location as the StarCCM+. The SW2D outer jets occur closer to the tank edges.
At 2D downstream the SW2D results again show seven defined peaks, with some merging, which is directly proportional to the velocity profile. The StarCCM+ results show a similar pattern to that seen at $1 \mathrm{D}$, but the inner jets have merged further, showing a similar profile to the experimental results. The peak velocities of the StarCCM+ inner jets are considerably higher than the 2-D program and experimental results.

The friction to mean velocity ratio profiles at 20D are similar to the depth-averaged velocity profiles at $20 \mathrm{D}$, as seen in Fig 9. The SW2D program results give maximum values at approximately $0.2 \mathrm{~m}$ and $1 \mathrm{~m}$, the span-wise locations of the outer jets. Minimum values occurred at the tank centre; this is the same pattern as the velocity profile. Both the experimental and StarCCM+ results show the opposite pattern, with maximum values at the tank centre and minimum values at the tank sides. The magnitude of the velocity ratios are similar, but the SW2D results are slightly higher than the experimental and StarCCM+ results.
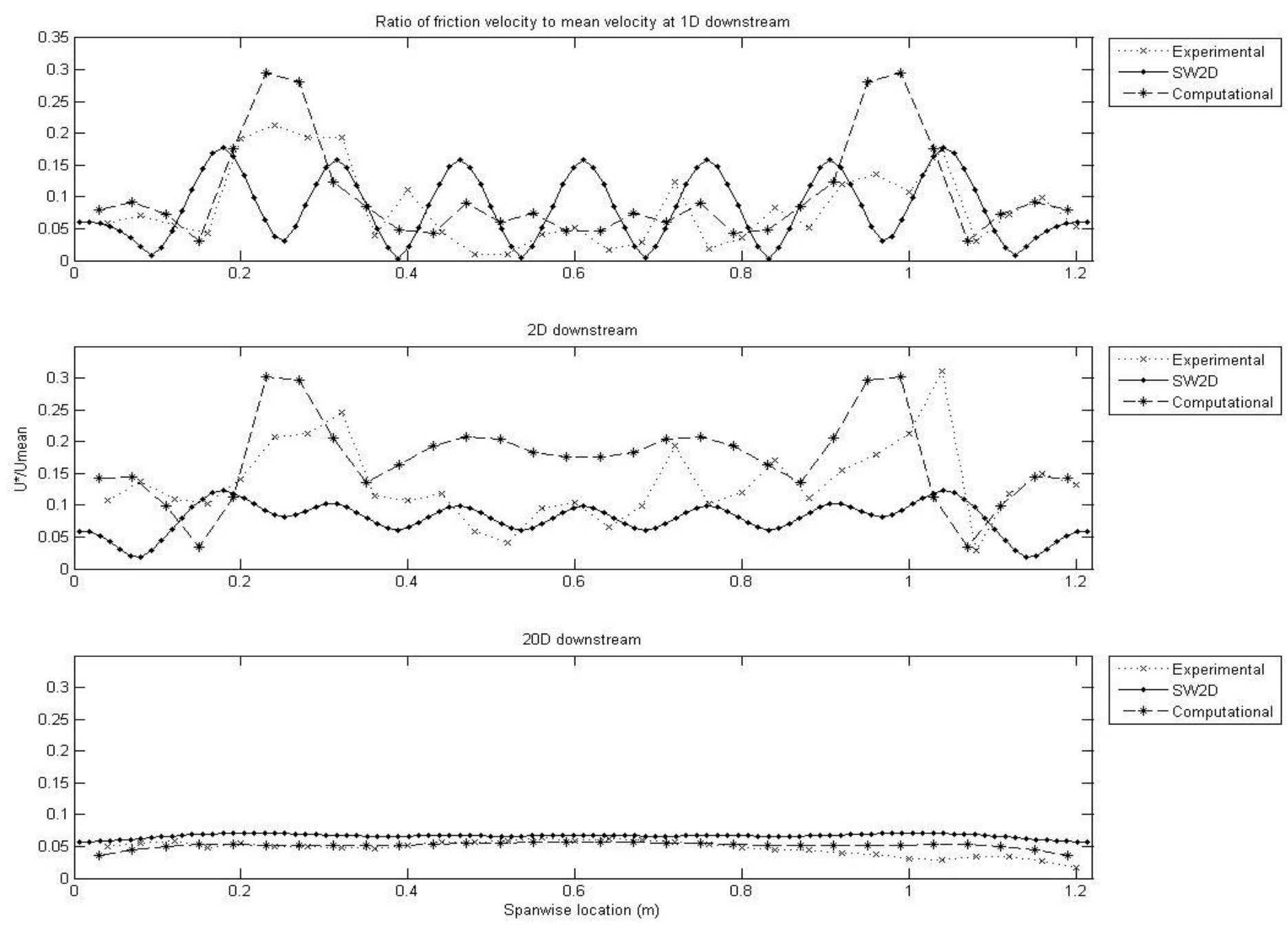

FIGURE 10: RATIO OF FRICTION VELOCITY TO CROSS-SECTION-AVERAGED VELOCITY AT 1D, 2D AND 20D USING EXPERIMENTAL, 2-D AND 3-D MODELLING 


\section{DISCUSSION}

Depth-varying velocity

At 1D downstream there is good correlation between the experimental results and 3-D computational results. They show the formation of eddies at the tank edges and velocity peaks directly downstream from the turbine culverts. Closer to the surface the inner jet strength reduces and starts to become negative. Close to the surface the flow is reversed, indicating vertical stream-wise eddies across the whole tank.

At 2D downstream there is still good agreement between the experimental and computational results. Eddies are still present and are shown to force the jets to the centreline causing merging. Positive outer jets are evident close to the surface, with negative flow between them.

At 20D downstream the stream-wise velocity remains fairly constant throughout the width, depth and breadth. As distance from the barrage increases the peak velocities decrease and merging of the jets occurs. The velocity range directly downstream from the turbine culverts also reduces due to spreading of the jets both vertically and horizontally.

\section{Depth-averaged velocity}

The depth-averaged velocities at 1D show that both the 3D results and 2-D results predict eddies at the sides of the tank. The results show peaks at the location of the seven turbine jets; the peaks predicted by the 3-D results are similar, but the 2-D results have a large velocity range.

At 2D, all of the methods produce similar results for the 3 inner jets, but closer to the tank sides the StarCCM+ predicts higher peak velocities and larger eddies than the 2-D SW2D program. The experimental results and StarCCM+ results predict eddies of the same size and velocity magnitude.

At 20D downstream the velocity magnitude is similar, both to the experimental and StarCCM+ results but also to the depth varied results. The profiles are slightly different, however, since the 3-D results show a maximum at the location of the outer jets and a minimum and the centre, whereas the 2-D results show the opposite results.

The depth-averaged velocity profiles are similar to those predicted at depths similar to the culvert exits, however are very dissimilar to the velocity profile close to the surface; this shows that close to the barrage (at 1D and 2D) the 2-D program could provide an indication of the velocity profile at the turbine height with some alteration to the program, such as the $\beta$ value, however the surface patterns cannot be determined with the program. The reversed flow that is seen close to the surface in both the experimental results and the 3-D computational results is not evident.

\section{Bed friction velocity}

The ratio of friction velocity magnitude to mean velocity magnitude has very varied results. At 1D the profiles are extremely different; the computational results are symmetrical, whereas the experimental results are asymmetrical, the maximum and minimum values are very different, plus the ratios at the eddy locations are dissimilar. The jet locations predicted by each analysis method are also completely different.

At 2D the same is true, however the experimental and SW2D results begin to show a similar pattern with peaks forming downstream from the culvert locations. The ratios at the eddy locations again are dissimilar sizes and magnitudes.

At 20D the velocity patterns seen previously are more evident, however due to the reduced velocity range the ratio range has also reduced, so the results are more similar than those close to the barrage.

Different methods of calculating the friction velocity could have led to this discrepancy; the wall function was assumed to extend to $0.01 \mathrm{~m}$ from the bed, so the velocities at this height were used to calculate the friction velocity, however this assumption may be need further analysis. Also, the friction velocity of the 2-D program was calculated using the coefficient of friction, $\mathrm{c}_{\mathrm{f}}$, which may be inaccurate; an alternative $\mathrm{c}_{\mathrm{f}}$ could be used to determine the effect it has on the results.

\section{CONCLUSIONS}

Three main issues were addressed in this paper: firstly, how the velocity varied with depth and distance from the barrage, secondly, whether two-dimensional depth-averaged modelling produces a reasonable result and thirdly, how the ratio of friction velocity magnitude to mean velocity magnitude varied with distance from the barrage and analysis method.

\section{Depth-varying velocity}

The results show that at depths corresponding to the culvert exits the profiles close to the barrage (at 1D and 2D) show that there are peak velocities downstream from the culverts and eddies at the tank edges. Close to the surface at these distances downstream the flow becomes more uniform across the tank and, in some cases, reversed. Far from the barrage (at 20D) the velocity profile is more uniform and does not vary greatly throughout the depth.

The 3-D computational modelling using StarCCM+ provides reasonable results that are comparable to the experimental results. Certain parameters, such as the mesh design, may need to be refined to produce better results, but the current results are acceptable for predicting depth-varying stream-wise velocities at $1 \mathrm{D}, 2 \mathrm{D}$ and $20 \mathrm{D}$.

\section{Depth-averaged velocity}

The depth-averaged velocity profiles are similar to those predicted at depths similar to the culvert exits, however are very dissimilar to the velocity profile close to the surface; this shows that close to the barrage (at 1D and 2D) the 2-D program could provide an indication of the velocity profile at the turbine height with some alteration to the program, such as the $\beta$ value, however the reversed flow that is seen close to the surface in both the experimental results and the 3-D computational results is not evident. 
Therefore, for close to the barrage analysis, these results show that the 2-D depth-averaged SW2D program does not produce reasonable velocity predictions for the flow close to the surface. Further from the barrage the predictions become more accurate and at 20D the 2-D results could be used as reasonable approximations of the surface flow.

For more accurate velocity predictions a 3-D model, such as the StarCCM+ model, provides better results, especially in terms of the main flow velocity magnitude and the eddy size and velocity magnitude.

\section{Bed friction velocity}

The results show that the ratio of friction velocity to mean velocity at $20 \mathrm{D}$ is approximately equal for the three analysis methods, however close to the barrage (at 1D and 2D) the results do not agree.

In order to assess the close to barrage bed friction the models may need to be refined; the SW2D model uses the coefficient of friction to determine the bed velocities, however this value may need to be altered to correspond to the experiments. Also, the experimental results assume that the near wall boundary condition extends to $0.01 \mathrm{~m}$ from the wall, which may need to be investigated. Further analysis of the calculation of the friction velocity is required.

\section{FUTURE WORK}

To develop this work further there are several possible options; firstly, more profiles should be evaluated, for example at $3 \mathrm{D}, 5 \mathrm{D}, 10 \mathrm{D}$ and $15 \mathrm{D}$ to determine at what point the $2-\mathrm{D}$ program produces reasonable results, as seen at 20D.

The experimental velocity fluctuation, and so the turbulence, can also be evaluated, which should lead to better computational modelling.

Further analysis of the friction velocities and the shear stresses acting on the bed could be undertaken to produce more accurate results; these could be assessed to determine how the sediment transport is affected by the installation of a barrage.
Further mesh sensitivity and time interval sensitivity studies can be conducted for both the 3-D and 2-D models to ensure convergence on a solution. The 2-D SW2D model can also be altered by varying the $\beta$ ratio and thus altering the amount of spreading.

After the models have been improved then modifications to the set-up can be investigated, such as including porous discs or orifice plates to represent the restriction to the flow through the culverts imposed by the turbines. Turbines could also be investigated, which may produce very different jet results due to the swirl induced by the turbine motion.

\section{REFERENCES}

Ahmadian, R. Falconer, R. A. Lin, B. (2010). Hydroenvironmental modelling of the proposed Severn barrage, Proceedings of the Institution of Civil Engineers, Energy, 163(3) 107-117.

Department of Energy, (1981). Tidal Power from the Severn Estuary. DEP Energy Paper 46, 198

Huai, W. and Toshihiko, S. (1999). 3-Dimensional numerical simulation for multiple vertical jets discharging into a shallow flowing ambient. Shiukexue Jinzhan/Advances in Water Science, $10(1), 1-6$.

Launder, B.E. and Spalding, D.B. (1974). The numerical computation of turbulent flows. Computer Methods in Applied Mechanics and Engineering, 3, 269-289.

Stansby,P.K. 2006 Limitations of depth-averaged modelling of shallow wakes, ASCE Journal of Hydraulic Engineering, 132(7), 737-740.

Xia, J. Falconer, R. A. Lin, B. (2010). Hydrodynamic impact of a tidal barrage in the Severn Estuary, UK, Renewable Energy, 35(7), 1455-1468. 